\title{
Correction to: The 3-Dimensional Fermi Liquid Description for the Iron-Based Superconductors
}

\section{Setsuo Misawa ${ }^{1}$}

Published online: 4 January 2019

(c) Springer Science+Business Media, LLC, part of Springer Nature 2019

\section{Correction to: J Low Temp Phys (2018) 190:45-66 https://doi.org/10.1007/s10909-017-1811-1}

The original version of this article unfortunately contained errors in equation and text.

In section 5, the heading "Nearly Ferromagnetic $\mathrm{Ba}\left(\mathrm{Fe}_{1-x} \mathrm{Co}_{x}\right)_{2} \mathrm{As}_{2}$ " should read as "Paramagnetic $\mathrm{Ba}\left(\mathrm{Fe}_{1-\mathrm{x}} \mathrm{Co}_{x}\right)_{2} \mathrm{As}_{2}$ ".

Equation (5.1) should read as

$$
\frac{\chi(0)}{\gamma(0)}=\frac{3}{\pi^{2}} \frac{\mu_{\mathrm{B}}^{2}}{k_{\mathrm{B}}^{2}} \frac{1}{1+F_{0}^{a}},
$$

Equation (5.5) should read as

$$
F_{0}^{a}=1.91 \text {. }
$$

Sentences which follow Eq. (5.5) should read: It is remarkable that the system is not nearly antiferromagnetic, but paramagnetic. The frequently mentioned statement that, because of the antiferromagnetic fluctuations, the system tends to be a non-Fermi liquid is not applicable to this system.

In the caption of Fig. 7, $\mathrm{LaFe}_{1-x} \mathrm{Co}_{x} \mathrm{As}_{0.89} \mathrm{Fe}_{0.11}$ should read $\mathrm{LaFe}_{1-x} \mathrm{Co}_{x} \mathrm{As}$ $\mathrm{O}_{0.89} \mathrm{~F}_{0.11}$.

In the reference section, the reference no 23 should read as " 23 . T. Okabe, Electrical conductivity of Fermi liquids, I and II. J. Phys. Soc. Jpn. 67, 2792-4178 (1998)”.

The original article can be found online at https://doi.org/10.1007/s10909-017-1811-1.

Setsuo Misawa

fermild@gmail.com

1 Department of Physics, College of Science and Technology, Nihon University, Kanda-Surugadai, Tokyo 101-8308, Japan 